\title{
REPRESENTACIÓN POLÍTICA Y MODERNIDADES MÚLTIPLES. LOS DIPUTADOS CATALANES EN LAS CORTES DE CÁDIZ (1810-1814) ${ }^{1}$
}

\section{POLITICAL REPRESENTATION AND MULTIPLE MODERNITIES. THE CATALAN DIPLATES IN THE CORTES OF CÁDIZ (1810-1814)}

\author{
María Gemma Rubí Casals \\ Lluís Ferran Toledano González \\ Universitat Autònoma de Barcelona
}

"Nos llamamos diputados de la nación, y no de tal o tal provincia; hay diputados por Cataluña, por Galicia, etc., más no de Cataluña, de Galicia, etc., entonces caeriamos en el federalismo, o llamase provincialismo, que desconcertaría la fuerza y concordia de la unión, de la que se forma la unidad" Antonio de Capmany ${ }^{2}$

SUMARIO: I- INTRODUCCIÓN. II- LAS ÉLITES DIRIGENTES CATALANAS Y LA CRISIS DEL ANTIGUO RÉGIMEN. III- LOS DEBATES PREPARATORIOS Y LA CONSULTA AL PAIIS. IV- LOS DEBATES CONSTITUCIONALES. V- A MODO DE BALANCE

Resumen: En el presente artículo pretendemos reflexionar sobre el tránsito del mandato imperativo al mandato representativo a través de la actuación de los diputados catalanes en las Cortes de Cádiz (1810-1814). Se analizan cómo los condicionantes derivados de los rigores de la Guerra napoleónica y de las necesidades del modelo de desarrollo económico de la Cataluña del siglo XVIII comportaron una no alineación mayoritaria de los parlamentarios catalanes a favor del liberalismo político y si en cambio se situaron dentro de un reformismo tardoilustrado. En definitiva, la tesis central del artículo es demostrar cómo existieron diferentes vías múltiples de modernización que condujeron también a que las élites territoriales se decantaran por canales de representación variables, a caballo entre el mandato imperativo y el representativo en función de los intereses que querian defender.

Abstract: In this article we try to analyze the transition from the imperative mandate to the representative mandate through the performance of the Catalan deputies in the Cortes de Cádiz (1810-1814). It is explored how the conditions derived from the rigors of the Napoleonic War and the needs of the model of

\footnotetext{
${ }^{1}$ Este artículo se enmarca en el contexto de los proyectos de investigación competitivos del "Plan Nacional de Investigación" HAR-2009-08989 y HAR2015-67173-P del Ministerio de Economía y Competitividad. Un primer y reducido esbozo se presentó en formato de comunicación en la 60 Conference Palermo and Messina, Sicily (Italia) (5-10 Septiembre de 2011) organizada por la International Comission for Representative Institutions.

${ }^{2}$ Discusión del proyecto de decreto sobre el tribunal de la Inquisición, Cádiz, Imprenta Nacional, 1813, pp. 471.
} 
economic development of the eighteenth century Catalonia led to a majority nonalignment of Catalan MP in favor of political liberalism and if instead they were within a reformism late-Enlightment. In short, the central thesis of the article is to demonstrate how there were different multiple ways of modernization that also led to the territorial elites opted for variable channels of representation, between the imperative mandate and the representative in terms of the interests they wanted to defend .

Palabras clave: Representación política; Parlamentarismo; Cortes de Cádiz; Cataluña Mandato imperativo; Culturas constitucionales; Historia contemporánea de España

Key Words: Political representation; Parliamentarism; Cortes of Cádiz; Catalonia Imperative mandate; Constitutional cultures; Modern History Spain

\section{INTRODUCCIÓN}

La emergencia y posterior consolidación de los regímenes políticos liberales durante el siglo XIX comportó adaptaciones distintas del principio del gobierno representativo. Los diversos discursos normativos subyacentes a las reformas electorales asignaron significados nuevos a los conceptos de representación social y politica. Se tomaron decisiones sobre diferentes variables como los limites de la capacidad de elegir y de ser elegido, la dimensión del censo electoral, la ampliación del sufragio, la delimitación de los distritos electorales, el grado de concordancia entre los derechos civiles y los derechos políticos, el escrutinio mayoritario o proporcional, entre otros. No obstante, existe una cuestión que dista de ser suficientemente tratada en la historiografia española más allá de lo recientemente escrito sobre en las las colonias americanas: la relacionada con la representación política de los territorios peninsulares y la integración de sus élites en la nueva nación liberal ${ }^{3}$.

Si esta cuestión la aplicamos al análisis del caso catalán nos encontrariamos con fuertes problemas derivados de la insuficiencia que poseen los modelos teóricos generales sobre la representación politica para explicar uno de los posibles ejes interpretativos sobre la singularidad histórica catalana. En las líneas que siguen nos ocuparemos del concepto de representación que tuvo el patriciado y la incipiente burguesía catalana, alineados mayoritariamente con la Ilustración católica y el proto-conservadurismo. En concreto, evaluaremos el discurso y las prácticas representativas que llevaron a cabo los diputados catalanes durante las Cortes de Cádiz (1810-1814), con la finalidad de contribuir a ilustrar el complejo tránsito del modelo de representación centrado en el mandato imperativo al mandato representativo ${ }^{4}$.

3 Véase como ejemplo el libro de Josep M. Fradera, La Nación imperial : derechos, representación y ciudadanía en los imperios de Gran Bretaña, Francia, España y Estados Unidos (1750-1918), Barcelona, Edhasa, 2015, 2 vols.

4 Juan Sisinio Pérez Garzón, Las Cortes de Cádiz. El nacimiento de la nación liberal (1808-1814), Madrid, Ed. Sintesis, 2007; Ignacio Fernández Sarasola, Los primeros parlamentos modernos de España (1780-1823), Madrid, Centro de Estudios Politicos Constitucionales, 2010. 
Es conocido el lento cambio semántico que experimentó el concepto de representación política. En este largo y dilatado proceso se pasó de una representación-espejo, entendida como una relación jurídica privada entre los cuerpos, estamentos, corporaciones o universidades -junto con las Cortes estamentales en las que estos grupos vehiculaban peticiones e instrucciones-, a una representación que tendió a participar de la gobernabilidad dentro del Estado, de modo que la relación dejó de ser privada para convertirse en pública. La representación política moderna fue esencialmente política, a diferencia de la del Antiguo Régimen que era esencialmente jurídica. Así, en la representación jurídica el mandatario actuaba por nombre y cuenta del mandante bajo un determinado y vinculante catálogo de instrucciones: el mandato ${ }^{5}$.

La representación política liberal insistió en preservar la independencia del diputado en relación al Gobierno, pero también respecto a los intereses de los distritos a los que representaba. No obstante, aunque la constitución francesa de 1791, entre otros textos constitucionales, prohibió expresamente que los diputados llevaran al parlamento instrucciones concretas de sus electores, el mandato imperativo no desapareció del todo y ambos principios convivieron. Los representantes o diputados ejercieron una función ambivalente al defender a la vez sus distritos y la nación, los intereses de sus electores y los de toda la nación. Unas tensiones mal resueltas originadas por un acoplamiento problemático de la cultura politica y jurídica liberal sobre una sociedad con proyectos distintos en su seno ${ }^{6}$. No fueron unas simples resistencias locales a la racionalización jurídica, sino expresión de dinámicas históricas que tenían su propia lógica. No fueron residuos del pasado. El proceso de national-building como minimo, debe analizarse tanto desde arriba como desde abajo más allá de las abstracciones discursivas ${ }^{7}$.

El caso catalán pone de relieve la necesidad de contemplar el análisis del tránsito de la representación política de Antiguo Régimen a la representación liberal de una manera compleja y no lineal. Tras la ruptura de 1808 la provincia de la Monarquía con uno de los dinamismos económicos más notable no manifestó una decidida apuesta por un nuevo orden politicamente liberal, aunque fue más sensible y sutil en su adhesión al liberalismo económico en las sesiones del Congreso. Tendriamos que preguntarnos si esta actitud era la propia de un comportamiento reaccionario o tal vez obedeció a que existían múltiples proyectos de modernidad. Una posición que explicaría que muchos de los parlamentarios catalanes se situasen pragmáticamente en el reformismo tardoilustrado. De ahí la admiración extendida por el sistema político imperial

5 Hanna Fenichel Pitkin, El concepto de representación, Madrid, Centro de Estudios Constitucionales, 1985.

${ }^{6}$ Federica Morelli "Entre ancien et nouveau régime. L'histoire politique hispano-américaine du XIX siècle" en Annales Histoire, Sicences Sociales, n ${ }^{\circ}$ 59-4, pp. 759-781. Traducción española en Historia crítica, $\mathrm{n}^{\circ}$ 33, Enero-Junio, 2007, pp. 122-155.

7 Un estado de la cuestión en Raffaele Romanelli (coord.), How Did The Become Voters. The History of Franchise in Modern European Representation, Hague-London-Boston, 1998; Antonio Annino (coord.), Historia de las elecciones en Iberoamérica, siglo XIX. De la formación del espacio politico nacional, Buenos Aires, Fondo de Cultura Económica, 1995; François Xavier Guerra, Modernidad e independencias, Madrid, Mapfre, 1992. 
británico en diputados tan relevantes como Antonio de Capmany o Ramón Lázaro de $\mathrm{Dou}^{8}$.

\section{LAS Élites DIRIgentes CATAlanas Y LA CRISIS DEL ANTIGUO RÉGIMEN}

Para conocer los conceptos de representación politica dominantes en un territorio es necesario acercarse a las características de éste, sus perfiles económicos y sociales, y sus culturas politicas. El Principado de Cataluña era un territorio cercano al millón de habitantes y que pasaba por una profunda crisis que ponia en tela de juicio la vieja sociedad señorial. Años antes, en 1714, tras la caída de Barcelona frente a las tropas borbónicas, se liquidó el régimen constitucional catalán basado en la teoria pactista, que abortó el proceso de modernización de su propia tradición representativa. Incluso Felipe $\mathrm{V}^{\mathrm{o}}$ de Borbón llegó a decir que las últimas cortes "habian dejado a los catalanes más repúblicos que el parlamento alusivo a ingleses". Al respecto, Angela de Benedictis ha calificado este sistema organizado en torno a las constituciones que regulaban la res publica como de "republicanismo monárquico". No obstante, antes de producirse la Guerra de Sucesión española (1701-1715), Cataluña había iniciado una importante transformación que la situaba como una de las partes más dinámicas, demográfica y económicamente, de la monarquía hispánica. Los ocupados en la industria eran mucho mayores en número que en cualquier otra región aunque, como en todas partes, se manifestaban signos de agotamiento del modelo a principios de siglo XIX ${ }^{9}$.

El carácter aparentemente contradictorio entre las opciones políticas y los intereses económicos y sociales de la clase dirigente catalana, en el preludio de la revolución liberal, ha provocado retos historiográficos de dificil resolución. Quizás las disparidades estructurales existentes y las diferencias de tempo histórico entre Cataluña y otros territorios de España puedan dar una explicación razonable. De entrada, una comprensión demasiado mecánica de la tensión entre lo económico y lo político, llevaría a un cul de sac interpretativo: así, mientras protagonizaba las dinámicas económicas más avanzadas quedaría aparentemente al margen del constitucionalismo liberal, sin destacados teóricos en lo político, ni figuras parlamentarias ni escritores reconocidos en el panteón liberal. Con Florencia Mallon 10, es necesario descentralizar estos procesos históricos, demasiado focalizados en el Estado, y abrirlos hacia los escenarios locales donde insertar los conflictos de poder y la acción de los sectores subalternos. De este

\footnotetext{
8 Ferran Toledano, "Modernidades múltiples: los proyectos económicos de Ramón Lázaro de Dou y Bassols y los cambios en los circuitos de opinión erudita (1742-1832)" en Jesús Astigarraga, Javier Usoz (éd.), L'économie politique et la sphère publique dans le débat des lumières, Madrid, Instituto internacional Xabier Maria de Munibe de Estudios del Siglo XVIII/ Casa de Velázquez, 2012, pp. 187-210.

9 Joaquim Albareda, Felipe $V$ y el triunfo del absolutismo: Cataluña en un conflicto europeo (1700-1714), Barcelona, Generalitat de Catalunya, Barcelona 2002; de Antoni Simón, Del 1640 al 1705. L'autogovern de Catalunya i la classe dirigent catalana en el joc de la politica internacional europea, Valencia, Publicacions de 1'Universitat de València, 2011. Angela de Benedictis, "Guerra, tirannide e resistenza negli scritti politici catalani", en Actas del Congreso L'aposta catalana a la guerra de Successió, 1705-1707, Barcelona, Museu d'Història de Catalunya, 2007, pp. 65-71.
}

10 Florencia Mallon, Campesino y nación: la construcción de México y Perú poscoloniales, México, Ciesas, 2003. 
modo podriamos vincular la revolución constitucional hispánica y atlántica con los conflictos sociales y políticos ocurridos en el pequeño rincón del Mediterráneo.

Conflictos con suficiente capacidad amenazadora como para producir estrategias precoces de moderación y acomodación de las clases dirigentes, que miraban no sólo hacia Cádiz sino hacia sus paisanos que comenzaban a decir que "mandaba el pueblo bajo y ninguno de los de respeto". Y es que había entrado en crisis también las formas de sumisión y de representación social propias de la sociedad estamental, donde a menudo el sector menestral agremiado o los negociantes enriquecidos se burlaban de las clases superiores, nobles y clero.

Se trataba, pues, de una conservadurización temprana, ayudada por la insuficiente influencia patricia catalana en los resortes del Estado. Cabe, entonces, trasladar buena parte de los problemas de construcción del national building español, no sólo a las supuestas debilidades del Estado, sometido a proyectos de nacionalización distintos, sino al carácter conflictual de la sociedad catalana y a los problemas de reproducción social, control y dirección política locales, en una crisis de gran envergadura.

En 1800, Barcelona era una ciudad en plena ebullición cercana a los cien mil habitantes, similar a Génova o Marsella. En los decenios anteriores fue la única ciudad del Mediterráneo que creció a un ritmo parejo al de Manchester y Liverpool, ciudades de tamaño semejante ${ }^{11}$. Contaba con un territorio de influencia cercano muy dinámico, compuesto por una decena de pequeñas ciudades de diez mil habitantes cada una, y que formaba -a diferencia de Madrid y de las principales urbes andaluzas- un área fuertemente interrelacionada. La producción agraria catalana (cereales, vinos y aguardientes para la exportación) e industrial (textil, aunque no en solitario), conformó unas redes de comercialización compenetradas -basadas en las tiendas, las factorias y las corresponsalias-, con proyección al interior catalán, hacia la península, al norte europeo y América. Esas redes fueron las que favorecieron la densidad de su conciencia industrialista, compartida más allá de Barcelona, por una tupida malla de ciudades medianas manufactureras.

La producción agraria orientada hacia el mercado fue la base del desarrollo económico catalán del setecientos, donde la elaboración de vinos y aguardientes tuvieron un papel clave. Los beneficiarios del crecimiento fueron tanto los grandes propietarios de mas detentadores del dominio útil, como los arrendatarios de los derechos señoriales y la pequeña nobleza local. En paralelo tuvo lugar el desarrollo manufacturero, basado en la industria tradicional lanera especializada en trapería de calidad, y la nueva industria del algodón con la estampación de indianas, que también sufrió grandes transformaciones con el cambio de siglo, el colapso del mercado colonial y la introducción de la mecanización de la hilatura.

En ese conjunto de procesos, los grupos sociales dirigentes se situaron socialmente entre la ordenación estamental y la creciente valoración de la riqueza como nueva categoría de distinción. Una prueba de ello es el ennoblecimiento de las élites comerciales y manufactureras, muchas de ellas con un marcado liderazgo en la Junta de Comercio -la principal organización que agrupaba

11 Pilar López, Naturales e inmigrantes en Barcelona a mediados del siglo XIX, "Barcelona. Quaderns d'Història", núm. 11, 2004, pp. 69-92. 
negociantes, fabricantes de indianas y fabricantes de hilados y tejidos-, o las estrategias económicas de la pequeña nobleza urbana tendentes a aburguesarse como hacendados o participando en los negocios de la ciudad. En ese contexto debemos situar la naturaleza social de los diputados catalanes en Cádiz ${ }^{12}$.

La modernización económica de la sociedad catalana no desembocó en una alternativa politica clara a la sociedad tradicional, sino que los conflictos bélicos y los vacíos de poder político precipitaron las cosas. Puede parecer una contradicción, pero la realidad es que hacendados y manufactureros creyeron en la compatibilidad real del crecimiento económico capitalista con un modelo político corporativo que asegurase un marco general de reformas "controladas". Un modelo donde los intereses de eclesiásticos y pequeña nobleza no quedasen al margen del mercado, sino que continuasen participando en la orientación de la reforma económica. Ese comportamiento se puso de manifiesto entre las elites catalanas de diputados en Cádiz y entre los miembros de las juntas locales surgidas tras el colapso del Antiguo Régimen simbolizado por el derrumbamiento del poder real en 1808. Una situación que había hecho compatible la existencia de un mercantilismo tardío de prácticas liberal económicas, opuesto al liberalismo politico de los discursos gaditanos, al menos hasta la nueva coyuntura revolucionaria de 1820 , donde el liberalismo político catalán fue ya visible y poderoso.

Las últimas investigaciones demuestran que en Cataluña, desde la implantación de los Borbones, estuvo gobernada por un régimen de excepción militar. En las coyunturas conflictivas excepcionales como las del alboroto contra el reclutamiento militar en 1773, o sobre todo en la Guerra contra la Convención francesa (1793-1795), se puso de manifiesto el uso por parte de los grupos sociales dominantes de estrategias de control y dirección política de carácter representativo y de base provincial ${ }^{13}$.

El discurso político e historiográfico sobre la unanimidad en España ha hecho creer que en las guerras contra la revolución primero (1793-1795) y contra Napoleón después (1808-1814), los españoles respondieron unidos como un solo hombre ante el enemigo común. La realidad fue muy distinta a esa imagen ${ }^{14}$. La guerra contra la Convención tuvo uno de sus escenarios principales en la frontera catalana con Francia. El descrédito de la autoridad militar y real -al menos en su dimensión local-, y la ausencia de un ejército poderoso y disciplinado, obligó a los sectores sociales dominantes a involucrarse en la "pública defensa del Principado". Y con ello a cuestionar y a adoptar una posición crítica frente a una

12 Una excelente síntesis en Jordi Maluquer, Història econòmica de Catalunya, segles XIX $i$ XX, Barcelona, Proa, 1998, así como Josep Fontana, La fi de l'Antic Règim i la industrialització, $1787-$ 1868, Barcelona, Edicions 62, 1988. De Francesc Valls, La Catalunya atlántica. Aiguardent $i$ teixits a l'arrencada industrial catalana, Vic, Eumo, 2003.

13 Gemma Rubí; Ferran Toledano, "La Guerra del Pendís o la fallida de l'autoritat de 1'Estat. Els manresans i la Guerra Gran (1793-1795)" en Marc Torras (coord.), Manresa, de la Guerra dels Segadors a la Guerra Gran, Manresa, Ajuntament de Manresa/Centre d'Estudis del Bages, 2014, pp. 297-329. Sobre la militarización de la sociedad catalana, véase Lluís Roura, Subjecció i revolta en el segle de la Nova Planta, Vic, Eumo, 2005.

14 Ferran Toledano, "La guerra de la independencia como exponente de la unanimidad española", en José M. Portillo, Xose Ramon Veiga, M. José Baz (ed.), A Guerra da Independencia e o primeiro liberalismo en España e América, Santiago, Universidade de Santiago de Compostela, 2009, pp. 69- 101. 
monarquía débil e impotente, posición que se radicalizó aún más durante la guerra napoleónica cuando las iras se dispararon contra el despotismo ministerial practicado por Carlos IV y su secretario, Manuel de Godoy, así como contra los mandos del ejército.

La necesidad de autodefensa comportó la militarización de la sociedad catalana por medio de cuerpos de voluntarios, somatenes o miqueletes, en un contexto latente de profunda desconfianza mutua del Estado hacia los catalanes, y de fuerte murmuración contra los oficiales militares castellanos. Una situación que condujo a trascender de su propio espacio privado corporativo -las familias, los negocios, la gestión religiosa-, para ocuparse públicamente de la guerra. Las fronteras tradicionales de lo público y privado se fueron rompiendo. Algo parecido pasó durante la guerra napoleónica en condiciones aún más dramáticas en cuanto a la supervivencia misma del Reino. El hecho de que las familias, los negocios y los intereses, se ocuparan de la guerra las obligó a tratar de participar en el reclutamiento y la financiación militar. Era una situación que ofrecía oportunidades personales -recibir premios, ampliar horizontes de reconocimiento social y político en el espacio periférico cortesano-, pero también de poner en peligro los delicados equilibrios sociales y activar la protesta plebeya. El liderazgo local reforzado por la estructura gremial y eclesial permitió la proyección y consolidación del poder de los hacendados y del resto del patriciado mercantil, siempre deseosos de incrementar las plataformas de representación pública.

Esta urgente necesidad permitió reforzar el papel politico territorial de las clases acomodadas catalanas con la creación de una Junta de la Provincia. Este órgano representativo funcionó entre diciembre de 1794 y enero de 1795, y estuvo tolerado con reservas por los funcionarios de la Audiencia y Capitanía General. Resulta excesivo considerarla una especie de "parlamento provincial", en términos empleados por Jean René Aymes ${ }^{15}$, pero sí una asamblea de representantes de las clases dominantes catalanas, de los hacendados y manufactureros, de los eclesiásticos y la pequeña nobleza. Una metáfora de los cambios sociales y económicos de la Cataluña del siglo XVIII, persuadidos que debian controlar directamente las formas de reclutamiento $y$ el sistema contributivo.

La movilización institucional vivida en el seno de las juntas hizo aflorar contradicciones dificilmente conciliables en medio de una crisis de autoridad tan extrema, acostumbrados como estaban los patricios a negociar con las autoridades borbónicas, incapaces de administrar directamente el país. En el fondo, lo que impulsaron los grupos dirigentes emergentes fue un proyecto que ampliara su representación y mejorara su ubicación en el seno de la monarquía la aspiración que el Reino asumiera la constitución política catalana como Provincia-, proyecto que, como comprobaremos, buscará apoyos más tarde en el nuevo escenario político de la Constitución de Cádiz.

15 Jean René Aymes, La guerra de España contra la Revolución Francesa (1793-1795), Alacant, Instituto de Cultura "Juan Gil-Albert", 1991, y el de Lluís Roura, Guerra Gran a la ratlla de França. Catalunya dins la guerra contra la Revolució Francesa, 1793-1795, Barcelona, Curial, 1993. 


\section{LOS DEBATES PREPARATORIOS Y LA CONSULTA AL PAÍS.}

Las ansias de representación politica territorial de los grupos dirigentes catalanes volvieron con fuerza a propósito del vacío de poder provocado por la guerra contra la invasión napoleónica entre 1808 y 1814, una coyuntura propicia para visibilizar los proyectos de articulación política de Cataluña en España. La ruptura revolucionaria se institucionalizó en el proceso constitucional de Cádiz que promulgó en 1812 la primera constitución de la moderna nación liberal. En esta ocasión, los diputados elegidos en el Principado de Cataluña expusieron en el nuevo espacio público sus proyectos políticos para España, y las condiciones del encaje territorial. A su vez, los deseos reformistas heredados del siglo XVIII tuvieron que convivir con el miedo a un protagonismo popular incontrolado, de manera que prevaleció la idea de orden evitando la movilización del pueblo al margen de las autoridades tradicionales ${ }^{16}$.

Cuatro fueron los modelos de representación política existentes en las memorias y respuestas procedentes de la Consulta al País que hizo la Junta Central en 1809 17. Esta Consulta se reguló mediante el Real Decreto de 22 de Mayo de 1809, y estaba dirigida a instituciones y autoridades como consejos, chancillerias y audiencias, las juntas provinciales, las autoridades religiosas, universidades y "sabios y personas ilustradas". Uno de los objetivos principales era el de escoger el modelo representativo que reuniera más adeptos para convocar unas Cortes. Las respuestas sirvieron a la comisión preparatoria de las Cortes para decidir el procedimiento de elección, su ámbito competencial y la naturaleza jurídica de su representación, al lado de aspectos vitales como la financiación y organización de la guerra ${ }^{18}$.

Según David Agrait, el primer tipo de respuestas respondió a lo que se ha denominado modelo historicista. En general, en España esa fórmula apelaba a la tradición constitucional medieval que mantenía la sociedad estamental y limitaba los poderes del monarca. Un segundo modelo fue el territorial provincial, semejante al anterior pero donde las provincias estarian directamente representadas en las futuras Cortes. El tercer arquetipo fue el corporativo territorial de la Nación, en el que ésta se identificaba con la reunión de las diferentes corporaciones estamentales y territoriales en una "gran corporación", sin que las juntas provinciales tuvieran una representación directa. Finalmente, el cuarto modelo respondió a una concepción corporativo-popular de la Nación, de carácter revolucionario, en el que un agregado indistinto de individuos defendía los derechos de la Nación frente al monarca.

Mientras el primer modelo representativo ponía el acento en el Reino como sujeto político, el segundo lo hacia en las provincias. Contrariamente, el tercero y cuarto modelo sustituían al reino y a las provincias por la Nación. Sin embargo, ambos atribuyeron significados distintos al concepto de nación: el tercer modelo

16 Ferran Toledano "El projecte català per a Espanya. La classe dirigent catalana i el procés constitucional de Cadis (1808-1814)" en Afers, nº 68, 2011, pp. 71-96.

17 David Agrait "Sobre el concepto de representación en los orígenes del constitucionalismo hispánico. Una reflexión historiográfica sobre los aspectos jurídico-políticos de la "Consulta al país": 1809-1810" en Revista juridica de la Comunidad de Madrid, n 24, 2006, pp. 153-226.

18 Un clásico en M. Isabel Arriazu "La consulta de la Junta Central al país", en Estudios sobre las Cortes de Cádiz, Pamplona, 1967, pp. 19- 117. 
la entendía como una gran corporación en la que se reunían los individuos y los cuerpos; contrariamente, el cuarto modelo identificaba a la Nación como la "única corporación posible en la que debian disolverse los individuos y los antiguos cuerpos, de forma que la "Nación" pudiese identificarse con el "pueblo" 19.

¿En qué modelo de los citados se encontrarían las respuestas a la Consulta enviadas desde Cataluña? Contamos primero con el testimonio protagonista de Antonio de Capmany -historiador ilustrado y de profesión militar-, como responsable de recoger las memorias y respuestas suscitadas por la Consulta el mes de junio de 1809, y redactar un Informe final, fechado en Sevilla el 17 de octubre de ese año. Para dar apoyo a sus tesis se propuso además elaborar un compendio histórico donde vindicaba la obra del jurista Lluís de Peguera ${ }^{20}$, un texto fundamental del parlamentarismo catalán. Dicho compendio no se pudo dar a conocer más que póstumamente, en 1821, con algunos añadidos y comentarios sobre otras culturas constitucionales -incluso se comparaba con los reglamentos de la cámara de los comunes inglesa-, aunque el centro de su relación era la catalana.

Más que un resumen, el Informe de 1809 trasmitía su propia interpretación: que la nación tenía que ser única y que su constitución tenía que prestar atención a las provincias de fueros, que eran una tercera parte de la monarquia ${ }^{21}$. Igualmente, recomendaba que una vez el Rey hubiese disuelto el Congreso al finalizar las sesiones, nombrara a una diputación de individuos para supervisar las infracciones constitucionales, y para ello utilizaba otra vez los recursos constitucionales catalanes: "Esta Diputación General, que en Cataluña, Aragón y Valencia se estableció a fines del siglo XIV para estos importantes objetos, $y$ para la recaudación y administración de las rentas públicas (...), retuvo firme $e$ ilesa su Constitución politica, civil y económica por tantos siglos". Precisamente, seguía insistiendo Capmany, aquellos tenían lo que le faltaba a Castilla, donde no existía una "autoridad nacional" que pudiese frenar las pretensiones de los reyes y los abusos que se pudieran cometer. ¿España, entonces, había tenido antes una Constitución? La respuesta de Capmany era afirmativa, pero esta constitución no la había tenido Castilla sino Cataluña, que sucumbió según sus palabras por la fuerza de las armas de Felipe IV y el derecho de conquista de Felipe V. Lo grave era que el desconocimiento de la Historia llevaba a no poder definir bien qué se entendía por Patria, Libertad, Independencia o Soberanía y ello era desestabilizador en términos politicos. En el futuro, al menos en su labor historicista, Capmany se convertiría en el referente de la generación liberal romántica catalana.

Al lado del testimonio personal anterior, las respuestas de otros miembros de la élite dirigente catalana tuvieron por denominador común su reformismo

19 David Agrait "Sobre el concepto de representación ...op. cit. pp. 24.

20 Ver la edición que cuenta con estudio introductorio de Eva Serra y Josep Fontana en Antonio de Capmany, Práctica y estilo de celebrar cortes en el reino de Aragón, principado de Cataluña y reino de Valencia, y una noticia de las de Castilla y Navarra, Barcelona, Ed. Base, 2007 (edición facsímil). Primera edición publicada en Madrid por la Imprenta de José del Collado en 1821 .

21 "Informe presentado a la Comisión de Cortes sobre la necesidad en que se hallaba la monarquía de una Constitución", 1809. Pocos años después se publicó su informe de forma anónima: Informe sobre Cortes nacionales, Cádiz, Imp. de Josef Niel, 1811. 
conservador: cortes estamentales y sufragio censitario, nueva constitución inspirada en los antiguos códigos, libertades económicas y adecuación liberal del sistema gremial, simplificación legal o uniformidad jurídica con reconocimiento del derecho privado catalán, entre otros ${ }^{22}$. Se optaba por la representación parlamentaria sin querer de ninguna manera extender los derechos políticos a ciudadanos. Deseaban limitar el poder del monarca para evitar el despotismo, y confiar en las bondades de una asamblea en la que estuvieran representadas las antiguas provincias del Reino.

Por su parte, Mariano Alegre, comerciante ennoblecido como barón de Castellet, en su respuesta a la Consulta recordaba que España se componía de diversos estados y cada uno con sus Cortes: "Cada uno tenía su modo particular de convocarlas y dictaba leyes con independencia y separación de los demás". Con la llegada de Felipe V, el sistema quedó imperfecto "porque no se hallaba en él la verdadera representación nacional». El barón se mostraba partidario de unas cortes estamentales pero admitiendo la elección de los cabeza de familia "que tengan arraigo por poco que sea, en casas, tierras, censos, diezmos o cualquier otra especie de propiedad, de modo que por ella paguen una contribución territorial' 23 . Parecida fue la respuesta del carcelario de la universidad de Cervera y prestigioso jurista Ramon Lázaro de Dou. Para éste la mejor forma de asegurar la observancia de las leyes del reino era "la formación de Cortes por un estilo semejante al antiguo de Cataluña, jurándose por el rey la observancia de lo que en ella se establezca", un parlamento que funcionase de manera estable e independiente de las mudanzas de la Corte, y fundar la felicidad del Estado en los "que poseen bienes y el influjo que tienen los propietarios en Inglaterra" 24.

Otro caso ilustrativo es el del miembro de la Junta de Comercio Juan Gispert, escogido diputado pero que no pudo viajar a Cádiz por fallecimiento, y que defendió unas Cortes formadas por la nobleza, el clero regular y secular, el tercer estado y los comerciantes, uno para cada provincia e incrementados en dos en el caso de las capitales maritimas que disfrutaran de consulados. En definitiva, se trataba de una versión modernizada del tipo de representación más cercano al modelo territorial provincial, adecuado también al tipo de cambios económicos y sociales que sufría entonces Cataluña. Propio también de la concepción de la nación como agregado de territorios, donde tan importante era la relación entre el diputado y la provincia, como la del diputado y la nación. Una actitud seguramente mucho más preocupada por la recuperación constitucional que no por la revolución constitucional, a pesar que con el desarrollo de las sesiones un número apreciable de diputados se identificaron claramente con el

22 Es opinión en parte de Maties Ramisa, Politics i militars a la Guerra del Francès (1808-1814), Lleida, Institut d'Estudis Ilerdencs, 2008, pp. 23 y ss. El clásico de Miguel Artola, Los orígenes de la España contemporánea, 2 vols, Instituto de Estudios Políticos: Madrid 1976.

23 Respuesta a la Consulta al País del Barón de Castellet, Vilanova i la Geltrú, 31 de Agosto de 1809. Archivo de la Corona de Aragón (A.C.A.), Fondo Guerra de la Independencia, Junta Superior, Caja 11.

${ }^{24}$ Los escritos de Ramón Lázaro de Dou y la Universidad de Cervera (Cervera, 29 y 17 de agosto de 1809, respectivamente), en el A.C.A., fondo Guerra de la Independencia...ibidem. 
tercer e incluso cuarto modelo, la nación de corporaciones o la nación de individuos ${ }^{25}$.

Paralelamente, las instrucciones que los miembros de la Junta Suprema del Principado de Cataluña entregaron a los diputados antes de su partida hacia Cádiz en agosto de 1810, fueron un prueba fehaciente de la estrategia política y del tipo de mandato preferido. Estas instrucciones estuvieron redactadas por Felipe Aner d'Esteve, el secretario de la junta y futuro y activo diputado. Su encargo se centraba en los criterios necesarios para la buena dirección de los ejércitos, el saneamiento de la hacienda y la formación de un gobierno provisional resolutivo. Lo más sustantivo era la voluntad que Cataluña conservara no solo "sus privilegios y fueros actuales, sino también recobrar los que disfrutó en el tiempo en que ocupó el trono Español la augusta casa de Austria", en el caso de que no se lograra la uniformización jurídica anhelada. La Junta manifestó además estar conforme con el establecimiento de un cuerpo nacional depositario de "de los derechos del Pueblo" y de las leyes constitucionales de la Nación. Un cuerpo que tendría que residir en la Corte pero -y aquí está lo significativo de la propuesta-, conviviendo en cada una de las provincias con "una Junta o Cuerpo de representación que tuviese el mismo objeto con sujeción y relación a aquel y con limitación a la esfera de su Provincia"26.

Esta reivindicación de los intereses territoriales se ha tendido a enlazar con una posición reaccionaria, equiparándola a la defensa de intereses corporativistas $\mathrm{y}$ por tanto no nacionales ${ }^{27}$, cuando éste fue un atributo presente entre los diputados catalanes a lo largo del siglo XIX, al margen de su orientación ideológica. Es más, en los discursos liberales sobre la representación, el apego a los intereses de los distritos fue una constante entre la mayoría de los diputados españoles, y no por ello definitoria de una posición no liberal o liberal ultraconservadora. Ni la reivindicación de las antiguas instituciones ni la defensa de la congruencia territorial pueden ser considerados como elementos constitutivos de un provincialismo reaccionario. ¿Cómo interpretar entonces que el revolucionario sevillano José Marchena recordara positivamente el constitucionalismo catalán de ochenta años antes? Marchena estuvo comprometido con la revolución francesa y luego con el gobierno de José $\mathrm{I}^{\circ}$, hermano de Napoleón. Criticó a los políticos a los que consideraba ignorantes porque no sabian que las Cortes de Aragón y de Cataluña "eran el mejor modelo de un gobierno justamente contrapesado". Que en España no existía ni homogeneidad nacional ni social, porque se trataba de un agregado de estados y pueblos distintos, y constataba efectivamente que la influencia de los municipios

25 Uno de los mejores es el libro de José M. Portillo Valdés, Revolución de nación. Orígenes de la cultura constitucional en España, 1780-1812. Madrid, CEPC, 2000; María Sierra, M. Antonia Peña, Rafael Zurita, Elegidos y elegibles. La representación parlamentaria en la cultura del liberalismo. Madrid, Marcial Pons, 2010.

26 Exposición de las principales ideas que la Junta Superior del Principado de Cataluña cree conveniente manifestar a los señores Diputados de esta Provincia que en representación de la misma pasan al Congreso de las próximas Cortes. Tarragona, 13 de agosto de 1810. Archivo de la Corona de Aragón, Junta Superior. Gobierno. Tomo II, folios 195-197.

27 Como ejemplo, la posición de uno de nuestros mejores historiadores constitucionales, Joaquín Varela Suanzes, "Nación, representación y articulación territorial del estado en las Cortes de Cádiz" en Jerónimo Zurita, 87, Zaragoza 2012, pp. 11-40. 
había sido muy notable. En este tema, puntualizaba que la "autoridad estaba más limitada en Cataluña que en ninguna otra parte"28.

Es cierto que el ambiente intelectual que existía durante estos años era propicio a la creación de un orden político nuevo que superara conflictos entre estamentos asi como entre territorios, pero la insistencia en lanzar al basurero de la historia a todos los provincialistas, formando parte de un rancio organicismo, no tiene sentido. Tampoco podríamos explicarnos entonces la conducta de José Garriga y Buach, un químico de prestigio y de proyección internacional, que fue designado por Joachim Murat como diputado de Cataluña representando el tercer estado en las sesiones preparatorias del estatuto de Bayona. Garriga, en la sesión de 27 de junio de 1808, después de la intervención de los diputados vascos en defensa de su régimen privativo propuso lo mismo para Cataluña pero fue apercibido por el presidente de la asamblea poniendo en duda su método de elección y asegurando que "ni la Cataluña tenía una Constitución particular" como las provincias vascas y navarra. De otro modo también parecería un anacronismo la defensa historicista del afrancesado Tomás Puig. Este último fue uno de los colaboracionistas más destacados con la ocupación francesa. Partidario de la abolición del régimen señorial y marcadamente contrario a cualquier tipo de entente con la Iglesia, como hombre de confianza del mariscal Augereau no dudó en utilizar un discurso lleno de referencias al orgullo económico, la defensa de la lengua catalana, la grandeza de las gestas medievales y su influencia en el Mediterráneo ${ }^{29}$.

Este discurso historiográfico hoy no tiene mucho sentido. La definición gaditana del concepto de ciudadanía remarcaba la condición de vecino y su vinculación primaria al territorio ${ }^{30}$. Hubo revolución constitucional, pero ella no debe interpretarse únicamente por sus resultados, sino junto con la perspectiva de las oportunidades y expectativas previas. Y para una parte apreciable de diputados lo que se abría era una oportunidad para realizar las reformas anheladas, una nación católica de pueblos y provincias.

Igualmente, la nación que se consagró en el texto gaditano tuvo un marcado carácter historicista, que apelaba a antiguas tradiciones constitucionales, sobre todo relacionadas con la Corona de Castilla, presente tanto en los discursos absolutistas como en los escritos liberales del eclesiástico e historiador del derecho Francisco Martínez Marina. Se ha señalado acertadamente que hubo una lucha de memoria entre dos legitimidades historicistas contrapuestas: la liberal, que radicaba el inicio del "desvio" de la historia española en la revuelta de los comuneros contra el poder imperial de Carlos $\mathrm{V}$ en el siglo XVI, o bien la

28 José Marchena (1768-1821) fue el primer traductor del Contrato Social de J.J. Rousseau al castellano, y partidario de una república federativa como la única posible en España. De este autor el manifiesto Aviso al pueblo español, 1793. Ver Juan Francisco Fuentes, José Marchena. Biografía politica e intelectual, Barcelona, Critica, 1989.

29 Ferran Toledano, "Historicisme i politica de la classe dirigent catalana en el debat constitucional gadità", en Agustí Alcoberro (a cura de), Entre la construcció nacional i la repressió identitària, Barcelona, Museu d'Història de Catalunya, 2012, pp. 205-218.

30 Marta Lorente, "La nación y las Españas" dentro de su libro: La nación y las Españas. Representaicón y territorio en el constitucionalismo gaditano, Madrid, Publicaciones de la Universidad Autónoma de Madrid, 2010, pp. 27-46. Un buen contrapunto en Hirotaka Tateishi, "La Constitución de 1812 y los conceptos de Nación/ Ciudadano", en Mediterranean World, 19 (2008), pp. 79-98. 
reaccionaria, que insistía en una lectura escatológica que veía el "desvío" revolucionario en la eterna lucha del bien contra el mal, que a su vez había protagonizado el humanismo, la reforma religiosa, la Ilustración y la masonería. Para ellos el siglo XVIII había estado lleno de errores ${ }^{31}$.

En estas observaciones, se puede entrever la insistencia en la vinculación de la experiencia constitucional pasada en el tipo de discurso que se estaba construyendo entonces sobre la denominada "constitución histórica española". El problema era que ésta tradición se identificaba básicamente con la castellana, cuando en realidad si alguna resonancia perduraba de esa cultura era en la tradición constitucional de la Corona de Aragón. Un imaginario cultural fortalecido a lo largo de los años anteriores a la revolución liberal, tal y como ha demostrado José Manuel Nieto Soria ${ }^{32}$. Un debate que no excluyó pero que atenuó las referencias a la tradición constitucional de la Corona de Aragón, cuando era considerada mucho más republicana que la de Castilla en cuanto a la limitación de los poderes del monarca.

\section{LOS DEBATES CONSTITUCIONALES}

La documentación disponible -intervenciones en las Cortes, cartas y representaciones, hojas de agitación- pone de relieve que la mayoría de los diputados catalanes fueron a la villa de la Real Isla de León y después a la ciudad de Cádiz como representantes o apoderados del territorio. En conjunto fueron 22 diputados para las Cortes Generales y Extraordinarias (1810-1813) y 12 para las Cortes Ordinarias (1813-1814), aproximadamente un 10\% respecto del total metropolitano ${ }^{33}$. Escogidos mediante un sufragio indirecto en tres fases entre los vecinos cabezas de família mayores de 25 años, guardando en las primeras elecciones una parte de las actas para las ciudades con derecho a voto (Tarragona, Lleida, Barcelona, Girona, Tortosa y Cervera), pero en su mayoria proclamados por una Junta Electoral Provincial. Los diputados tuvieron instrucciones precisas y periódicas de la Junta Superior de Cataluña, de los diferentes Congresos Provinciales celebrados en Manresa, Solsona y Tarragona, y de la Diputación de Cataluña -como organismos que representaban la Provincia y atendian sus necesidades fiscales, militares y de orden público-, explicando lo que debian incluir en los debates y negociar con la Regencia.

La clasificación ideológica canónica de los diputados establece una división entre absolutistas, realistas (reformistas) y liberales, dejando aparte los diputados americanos. Esta es una división demasiado rígida que no recoge la pluralidad de

31 Tesis de Santos Juliá, Historias de las dos Españas, Taurus: Madrid 2004.

32 Ver el excelente estudio de José M. Nieto Soria, Medioevo constitucional. Historia y mito político en los orígenes de la España contemporánea (ca. 1750-1814), Madrid, Akal, Madrid 2007. Autor "Historicisme i política de la classe dirigent catalana en el debat constitucional gadità" en Agustí Alcoberro y Giovanni C. Cattini (a cura di.), Entre la construcció nacional i la repressió dientitària. Actes de la Primera Trobada Galeusca d'Historiadores $i$ d'Historiadors. Barcelona, 10 i 11 de desembre de 2010, Barcelona, Museu d'Història de Catalunya, 2012, pp. 203-218.Ver también, del especialista en el estatuto de Bayona, Jean Baptiste Busaall "Diversité institutionnelle et mythe de la constitution historique dans la Révolution libérale: la Breve noticia del Reyno de Navarra de Hermida (1811)" en Anuario de historia del derecho español, N$^{\circ}$ 74, 2004, pp. 333-408.

33 Además de diversos artículos, la referencia actual es Quintí Casals, La representación parlamentaria en España durante el primer liberalismo (1810-1836), Universitat de Lleida, 2014. 
matices y la diversidad de dinámicas políticas e ideológicas encontrada entre los diputados catalanes. Es correcto considerar que la iniciativa política correspondió a liberales y reformistas en las primeras Cortes, mientras que en las segundas se cedió terreno a posiciones defensivas, y eso vale también para los diputados catalanes. Numéricamente, la adscripción ideológica de los representantes catalanes produjo un empate técnico entre realistas y liberales $\left(\begin{array}{lll}13 & \text { y } & 9\end{array}\right.$ respectivamente) y absolutistas (21). No obstante, las diferencias son más nítidas entre diputados catalanes y metropolitanos en lo relativo a su condición socioprofesional. Según nuestros cálculos y los de Quintí Casals ${ }^{34}$, el porcentaje de eclesiásticos y de cargos administrativos y magistrados catalanes es inferior al español -que fueron el sector mayoritario en el hemiciclo gaditano-, mientras que es superior el de abogados, comerciantes, negociantes y nobles hacendados. No obstante, recordemos que en Cataluña la Iglesia y la pequeña nobleza hacía tiempo que estaba muy involucrada en la economia orientada hacia el mercado.

Los diputados además atendieron las peticiones de la Junta de Comercio y solicitaron la opinión de la provincia en los debates relativos a la división provincial y la fiscalidad, así como en la supresión del tribunal de la Inquisición que suscitó controversias en su seno. Con el desarrollo de las sesiones, algunos diputados se convirtieron en enlace estable y portavoces oficiosos de las instituciones catalanas y la tribuna gaditana; primero Ramón Lázaro de Dou y Felipe Aner d'Esteve, y más tarde por los liberales de diversas tonalidades José Anglasell, Andrés Oller y Juan de Valle.

La mayoría de diputados catalanes -con la excepción de Antonio de Capmany, José Espiga, Fernando Navarro y algún otro- se irrogaron una idea de la representación expresada a través del mandato imperativo del territorio, que establecía canales de mediación entre los súbditos y el soberano, representando al pueblo y no a la nación en un sentido liberal. El mes de enero de 1813 se produjo un célebre debate sobre la supresión o no del tribunal de la Inquisición, expresivo de algunos de los problemas que acarreaban los distintos conceptos de representación. En él participaron conspicuos diputados liberales, como Agustín de Argüelles o el conde de Toreno, junto a Antonio de Capmany y otros diputados catalanes como el reformista Juan de Valle o el absolutista Jaime Creus.

Resulta pertinente distinguir dos aspectos. El primero consiste en interpretar el debate en clave politica y jurídica, es decir, la abolición del Santo Oficio en tanto que su existencia era incompatible con el principio de la soberanía nacional y los presupuestos ideológicos liberales. En este ámbito Capmany rechazó claramente la Inquisición porque se trataba de un cuerpo independiente del estado. Por su lado, de Valle se mostró más pragmático puesto que si bien su existencia era contraria a la constitución, era partidario de su reforma y adaptación constitucional porque en aquélla fase de la guerra la supresión total del tribunal podía desmovilizar a un pueblo fanatizado por la religión. El canónigo Jaime Creus, junto a un buen número de diputados, se opuso frontalmente a la desaparición del Santo Oficio, expresando sus temores en sesión parlamentaria,

${ }^{34}$ Ferran Toledano, "El projecte català per a Espanya....op.cit., pp. 82-84. De Quintí Casals,"E1 proceso electoral en España y Cataluña según la Constitución de 1812", en Rúbrica Contemporánea, 1, Universitat Autònoma de Barcelona, 2012, 24 pp. 
en la prensa o dando apoyo a manifiestos ${ }^{35}$. En todo caso, los miedos excitados por las consecuencias de la supresión deben de entenderse en estrecha relación con los recelos producidos por la libertad de imprenta y la politización del pueblo bajo.

Un segundo aspecto tiene que ver con el tipo de representación y los usos discursivos de las culturas constitucionales, lo que la historiografia ha señalado como el mito de la constitución histórica o la constitución antigua. Tanto la mayoria de diputados catalanes partidarios del mantenimiento de la Inquisición, como los detractores -Capmany, de Valle-, utilizaron a su favor la capacidad de las antiguas cortes catalanas para denunciar sus abusos, ya fuera del siglo XVI como a principios del siglo XVIII ${ }^{36}$. No obstante, lo que sacó de quicio a los abolicionistas fue que los diputados reticentes pidieran consultar a su provincia antes de pronunciarse y validar la opinión de sus representados. La consulta destruiría la representación nacional; "pura democracia" para Agustín de Argüelles, "anarquía desoladora" para el conde de Toreno. El diputado Juan Nicasio Gallego llegó a ironizar con la aprobación de un extravagante documento que rezara: "las Cortes generales y extraordinarias y los diputados de Cataluña decretan...".

No obstante, la intervención más destacada la debemos una vez más a Antonio de Capmany, el 21 de enero de 1813. Recordó a sus compañeros de provincia que los poderes de sus escaños les otorgaban plenas facultades decisorias. Lo hacia mediante materiales constitucionales provinciales, otra vez procedentes de la obra de Luís de Peguera, para argumentar que en el pasado los representantes catalanes que acudian a sus Cortes podian decidir de igual manera que en Cádiz, sin atender a casos particulares. Así mismo, en réplica a los diputados catalanes que cuando tomaban la palabra decian ser de Cataluña, Capmany precisaba "Nos llamamos diputados de la nación, y no de tal o tal provincia; hay diputados por Cataluña, por Galicia, etc., más no de Cataluña, de Galicia, etc., entonces caeriamos en el federalismo, o llamase provincialismo, que desconcertaría la fuerza y concordia de la unión, de la que se forma la unidad"37.

35 El 4 de Enero firmaron una representación a las Cortes los diputados Jaime Creus, Francisco Morros, Francisco Aytés, el marqués de Tamarit, Juan Bautista Serrés, Francisco Papiol, Ramón de Lledós, José Vega, Ramón Lázaro de Dou y Francisco Calvet. Además se publicó la Representación de la Diputación provincial de Cataluña contra el abuso de la libertad de imprenta y en favor de la Inquisición, Berga, 7 de febrero de 1813; la firmó José Anglasell, en calidad de secretario de la Diputación, abogado ilustrado en temas económicos, reformista moderado, poco después sería diputado en las cortes ordinarias. Tener en cuenta también la Instrucción pastoral de los ilustrísimos señores obispos de Lérida, Tortosa, Barcelona, Urgel, Teruel y Pamplona, al clero y pueblo de sus diócesis, reimpresa en Mallorca, 1814. Aantoni Sánchez, "Eclesiásticos catalanes y las Cortes de Cádiz", en Anuario de Historia de la Iglesia, vol. 19, 2010, pp. 119-140.

36 Jordi Roca, "Las Cortes de Cádiz: génesis del liberalismo romántico catalán” en Trienio: Ilustración y Liberalismo, núm. 61, (2013), pp. 73-124; Beatriz Cárceles, "Reforma/ abolición del Tribunal de la Inquisición (1812-1823). La constitución de la autoridad absoluta", en Manuscrits, núm. 17, 1999, pp. 179-199, y Emilio La Parra y M. Angeles Casado, La Inquisición en España. Agonía y abolición, La Madrid, La Catarata, 2013.

$37 \mathrm{El}$ subrayado en el original. Discusión del proyecto de decreto sobre el tribunal de la Inquisición, Imprenta Nacional, Cádiz 1813, pp. 471. La frase anterior de Juan Nicasio Gallego en la pàgina 327. 
Hemos visto a menudo cómo el propósito de Capmany de incorporar la cultura constitucional catalana a la retórica de la "constitución histórica" española -de igual modo que Ramón Lázaro de Dou hizo con el derecho catalán respecto al derecho patrio español de base castellana-, no se contradice con el deseo o la necesidad de fortalecer la unidad de acción nacional. Por eso este diputado se manifestó contrario a las relaciones bilaterales entre diputados de provincias con la Regencia o embajadas extranjeras, sin previo aviso a las Cortes. Y no deja de ser muy significativo que ese "provincialismo" apareciera parejo al federalismo o a la democracia, y que en los debates se advirtiera del peligro ambivalente -reaccionario o democrático- de la política provincial, en la medida que su ejemplo lo pudieran seguir las Filipinas, Chile u otros territorios. A este propósito el conde de Toreno alegó que "ni el demócrata más exaltado hubiera presentado jamás proposiciones que, en mi entender y con permiso de los señores, son irracionales y perturbadoras del orden público"38.

En contraste con la posición anterior, el diputado Juan de Valle, conocedor también como el grueso de las elites catalanas de su cultura constitucional, no dudó en demostrar las incompatibilidades entre las antiguas Cortes catalanas y el Santo Oficio. A pesar de ello, estuvo meses esperando instrucciones de su provincia, porque para él lo determinante era la concreción y repercusión práctica del decreto. Reformista inclinado hacia el liberalismo, firme defensor del proteccionismo y agente de los intereses de negociantes e industriales catalanes, de Valle solicitó también a la Junta qué posición tenía que adoptar sobre la reforma de los códigos civil, criminal y de comercio, reclamando que se le mandara un código municipal de la Provincia. Este diputado, que como abogado había administrado los bienes de la casa ducal de Medinaceli en Cataluña, no tuvo reparos en pedir la supresión de las señorias y "todo lo que huela a feudalismo". Por lo tanto, ser diputado de la provincia y liberal, con todos sus matices, no tenía porque ser antagónico. Por último, Andrés Oller, uno de los diputados liberales catalanes más incisivos en las Cortes ordinarias y muy implicado en la reforma del régimen constitucional, se consideró a sí mismo "abogado de la provincia".

\section{A MODO DE BALANCE.}

En suma, los diputados catalanes prefirieron un modelo representativo en el que la provincia tenía que desempeñar un rol politico, y no por ello hay que tacharlos a todos de reaccionarios. Que la idea rectora fuera la nación soberana sacralizada no impidió que los intereses de las antiguas provincias no fueran reivindicados apelando al pasado como un recurso retórico, como argumento de autoridad, porque confiaban en la tradición constitucional catalana, o simplemente por razones pragmáticas, por necesidad de atender a los problemas más acuciantes de la guerra. La legitimación desdoblada del pasado impregnó como es sabido el discurso liberal y reaccionario español. En consecuencia, sólo una lectura superficial conduciría erróneamente a considerar que estos diputados se alineaban con los parlamentarios absolutistas -que a menudo se confunden con los estrictamente realistas reformistas- sólo porque eran partidarios de un modelo no individualista de representación politica, admiraban el régimen

38 Ibídem...op.cit., pp. 226, correspondiente a la sesión de 11 de enero de 1813. 
constitucional catalán o necesitaban consultar con su provincia para determinar su posición en los debates.

El conflicto de representación se repitió años más tarde, en las cortes del Estatuto Real en marzo de 1835, tras pedir diversos diputados (denominados procuradores) un trato igualitario y proporcional al esfuerzo fiscal de todas las provincias de la monarquía. En él, como en 1813, se volvió a señalar que los representantes catalanes incurrian en el error de verse como diputados de Cataluña y no por Cataluña. La preposición "de" sólo era identificable con la nación, y por ello el debate tuvo sus efectos en la definición del ser político nacional cuando el dirigente liberal moderado y excelente orador, Antonio Alcalá Galiano, advirtió haber oído repetir -insistimos en la relevancia de la reiteraciónesa expresión equivoca: "Señores, uno de los objetos principales que nos debemos proponer nosotros es hacer a la nación española una nación, que no lo es ni lo ha sido hasta ahora"39. En este tipo de debates se trataba de frenar la intención gubernamental de aumentar la presión fiscal sobre los territorios de la antigua Corona de Aragón, lo que se consideraba un castigo ${ }^{40}$.

Desde la segunda mitad del siglo XVIII, para las elites catalanas la representación política estuvo unida a las necesidades de interlocución de la provincia. Sin embargo, a partir de 1813 y 1814 la expresión "provincialismo" pasaría a designar en el vocabulario político español una actitud egoísta, cegada a sus propios intereses. Durante años los diputados catalanes en la tribuna del congreso y senado españoles, se vieron obligados a neutralizar las connotaciones negativas de la palabra. El hecho revelaba una posición subordinada, no sólo de los diputados catalanes, sino también de los aragoneses y valencianos, en la hegemonía del discurso parlamentario español. Una posición que en realidad sublimaba la Nación o, mejor dicho, al Estado, una vez vaciado del contenido semántico revolucionario de las primeras asambleas representativas liberales y de la potencialidad disgregadora -la hidra federal- abierta en América.

Debemos ver las elecciones como prácticas culturales que siguen un camino paralelo al de las normas, y que conciernen instituciones diversas, no necesariamente políticas. Precisamente en España el casuismo jurídico tuvo que hacer un gran esfuerzo para poder imaginar y controlar esa diversidad. También se imaginó la "razón", que en buena parte trasladaba a la nación el mito unitario neutralizador del efecto disolvente que a su juicio tenian potencialmente las

39 Diario de las Sesiones de Cortes. Estamento de Procuradores, Madrid 12 de marzo de 1835 , núm. 168, pp. 1861-1869. Antonio Alcalá Galiano (1789-1865), Conde de Casa Valencia, será diputado en nueve legislaturas y provenía de una influyente familia de militares; dijo a continuación en su discurso "Una de las grandes ventajas que gozan los gobiernos representativos es la proporción que tienen de hermanar los intereses, reuniéndolos en un solo centro, que es a lo que nosotros debemos dirigir nuestras tareas”. Pp. 1867. El procurador Joaquín Palaudarias respondió, entre otras cosas, que no se conocía suficientemente la realidad económica catalana y que ello llevaba a exagerar su riqueza: "comparándola a una mina fecunda e inagotable, y se estimula al gobierno a explotarla”. Pp. 1867. Es significativo que el antiguo diputado y jurista presente en Cádiz, Ramón Lázaro de Dou, publicó a raíz de este tipo de debates el folleto Equivalencia del Catastro de Cataluña con las rentas principales de Castilla, Cervera, Imprenta de la Universidad, 1822 .

40 Borja de Riquer; Gemma Rubí; Ferran Toledano; Oriol Luján; Núria Rius, "MPs representing Barcelona at the beginning of the Spanish parliamentary system (1834-1854)", Parliaments, Estates and Representation, vol. 35, 2015, Rouletge, pp. 46-65. 
provincias ${ }^{41}$. Y en esto España no fue diferente a lo sucedido en Europa y América, en el sentido que perseguía la conciliación de la comunidad política imaginando la unidad fundamental de la nación.

La oposición antiguo (mandato imperativo) a moderno (mandato representativo), responde a un modelo teleológico, similar al que opone organicismo o corporativismo a individualismo. Obedece al canon oficial del discurso de la modernidad que sacralizó el liberalismo burgués, unitario y estatalista. Los procesos fueron mucho más complejos, en Cataluña, España y el mundo entero ${ }^{42}$. De igual modo se debe desdramatizar el congénito déficit de individualismo español y catalán, condicionado por el peso de la nación católica en la constitución ${ }^{43}$. $\mathrm{Ni}$ en Europa ni en los Estados Unidos, los valores individualistas fueron predominantes hasta mucho más tarde ${ }^{44}$.

Fecha de envío / Submission date: 4/12/2017

Fecha de aceptación /Acceptance date: 3/01/2018

41 Elias J. Palti, "El voto y el XIX desconocido" en Istor. Revista de Historia Internacional, 17, México, 2004, pp. 43-59.

42 Nuevamente, Elias J. Palti, "La modernidad como problema (El esquema "de la tradición a la modernidad" y la dislocación de los modelos teleológicos)", en María Emilia Prado (org.), Tradição e Modernidade no Mundo Ibero-Americano. Atas do Coloquio Internacional, Rio de Janeiro, Universidade do Estado do Rio de Janeiro/Grpesq/CNPq, 2004, pp.29-36.

43 Ver el interesante dosier dirigido por Gregorio Alonso y Richard Cleminson "Sujetos frágiles: the fragility of the liberal subject in the Modern Hispanic Word" en Journal of Iberian and Latin American Studies, n. 22, 2016.

44 Verena Stolcke, "Gloria o maldición del individualismo moderno según Louis Dumont", en Revista de Antropologia, vol. 44, núm. 2, Sao Paulo, 2001, pp. 7-37. Bernard A. Shain, The Myth of American Individualism. The Protestant Origins of American Political Thought, Princeton, Princeton University Press, 1996. Para España, basándose en Liah Greenfeld, José Alvarez Junco, "Todo por el pueblo. El déficit de individualismo en la cultura política española", Claves de Razón Práctica, $\mathrm{n}^{\circ}$ 143, 2004, pp. 4-9. 